\title{
Perfectionism, Interactional Justice and Job Performance: A Trait Activation Perspective
}

\author{
Myungsun Kim ${ }^{1}$, Seckyoung Loretta Kim ${ }^{2, *}$, Seung Yeon Son ${ }^{3}$ and Seokhwa Yun ${ }^{1}$ \\ 1 College of Business Administration, Seoul National University, Seoul 08826, Korea; \\ myungsun.kim7@gmail.com (M.K.); syun@snu.ac.kr (S.Y.) \\ 2 College of Business Administration, Incheon National University, Incheon 22012, Korea \\ 3 Graduate School of Defense Management, Korea National Defense University, Nonsan-si 33021, Korea; \\ faithnet153@kndu.ac.kr \\ * Correspondence: loretta@inu.ac.kr
}

Citation: Kim, M.; Kim, S.L.; Son, S.Y.; Yun, S. Perfectionism, Interactional Justice and Job Performance: A Trait Activation Perspective. Sustainability 2022, 14 , 1117. https://doi.org/10.3390/ su14031117

Academic Editor: Christian Vandenberghe

Received: 30 November 2021

Accepted: 16 January 2022

Published: 19 January 2022

Publisher's Note: MDPI stays neutral with regard to jurisdictional claims in published maps and institutional affiliations.

Copyright: (c) 2022 by the authors. Licensee MDPI, Basel, Switzerland. This article is an open access article distributed under the terms and conditions of the Creative Commons Attribution (CC BY) license (https:/ / creativecommons.org/licenses/by/ $4.0 /)$.

\begin{abstract}
Drawing on trait activation theory, this research explores the intrapersonal consequences of perfectionism in the workplace by examining the relationships between self-oriented perfectionism (SOP) and two distinct job performance dimensions, i.e., task performance and organizational citizenship behavior (OCB) and the moderating role of interactional justice on these relationships. Using field data collected from 121 employee-supervisor dyads in South Korea, we found a unique and incremental predictive power of employee SOP on job performance, specifically task performance. Moreover, the results showed that the interaction effect of employee SOP and interactional justice on OCB was significant, such that the trait of SOP was activated to enhance OCB when interactional justice was low. Theoretical and practical implications are discussed.
\end{abstract}

Keywords: perfectionism; interactional justice; task performance; organizational citizenship behavior (OCB); trait activation theory

\section{Introduction}

As the business culture of today emphasizes meritocracy and competition, perfectionism has received increasing attention from various fields including psychology, education, sport science, medicine and organizational behavior [1,2]. To achieve and sustain competitive advantages, organizations often expect and encourage employees to possess the quality of perfectionism, which refers to an individual's tendency of setting high standards, struggling to reach those standards and assessing oneself rigorously [3]. Historically, perfectionism was known to be linked to various forms of negative outcomes, such as depression, negative affect and burnout [4]. Although Hamachek [5] has noted that perfectionism has both positive and negative aspects, the positive side of perfectionism has not been the subject of much attention, especially in work settings. However, considering its unique features, such as the pursuit of excellence and flawlessness, perfectionism is expected to be a powerful predictor of employee attitudes and behaviors [2]. Accordingly, this research aims to bridge the gap in the literature on perfectionism, justice and job performance in organizational settings.

The current research contributes to perfectionism literature by investigating the effects of perfectionism on two different aspects of job performance: task performance and organizational citizenship behavior (OCB) in the workplace. Ocampo et al. [2] argued the importance of perfectionism in understanding various employee attitudes and behaviors from an organizational behavioral perspective. Scholars have noted the multidimensional nature of perfectionism [1,4], which allows the differential effects of perfectionism on outcomes depending on the dimensions [2]. For example, scholars have noted the adaptive nature of self-oriented perfectionism and maladaptive nature of socially prescribed perfectionism [1]. Recognizing such nature of perfectionism, this study focuses on self-oriented perfectionism 
(SOP), which is a core dimension of the multidimensional perfectionism concept developed by Hewitt and Flett [3]. Hewitt and Flett's [3] model offers three dimensions that reflect both intrapersonal (i.e., self-oriented perfectionism) and interpersonal (i.e., other-oriented and socially prescribed perfectionism) perspectives on perfectionism [2]. Given that SOP comprises "internally motivated demands to strive for perfection and to be perfect" [2], SOP seems to fit this study to examine the intrapersonal consequences of perfectionism in the workplace such as how perfectionism influences employees' job performance.

Specifically, SOP refers to self-directed perfectionistic tendency and behaviors, including setting high standards and stringently assessing oneself, attempting to gain perfection and striving to avoid failures [3]. SOP can exert its unique influence as an individual trait in determining individual employees' job performance at work, as each dimension of perfectionism is known to affect different aspects of individual functioning in work domains [6]. As argued by Frost et al. [7], SOP is linked to good work habits and efforts for high achievement. Additionally, SOP reflects a strong, motivational component to be perfect which can help employees achieve outstanding performance at their work $[8,9]$. Hence, our research selects SOP as an antecedent of the employee's two job performance dimensions since it is more applicable to work settings and related to positive work outcomes than other dimensions of perfectionism (i.e., other-oriented perfectionism and socially prescribed perfectionism).

According to trait activation theory $[10,11]$, some situations can provoke the influence of traits on performance by offering trait-relevant cues. Other environments, on the contrary, can negate the impact of a trait by providing powerful extrinsic rewards in terms of clarity and severity. Understanding the influence of situations can provide additional insights into the complexities of employees' behaviors and performance [12]. Based on previous research $[13,14]$, we argue that a supervisor's fair treatment is the most available and powerful information or resource for employees in determining their work behaviors. To address the recent call for more research on additional, situational factors that may alter the impact of perfectionism in the workplace [2], this research explores interactional justice as a critical, contextual factor that moderates the SOP-job performance relationship.

This study has two major purposes. First, the present study contributes to perfectionism literature by testing the effects of SOP on an employee's task performance and OCB in the workplace. By doing so, this study contributes to a better understanding of perfectionism by demonstrating its positive implication in terms of individual functioning at work. Second, we apply trait activation theory and investigate the moderating role of interactional justice in the aforementioned relationships. Specifically, we intend to exhibit how the trait of SOP is activated to promote two different job performance dimensions when there is a low level of interactional justice.

The following sections explain the concept of job performance and its importance to organizations and then develop the hypotheses by outlining the theoretical and empirical justification for perfectionism, especially SOP, as a predictor of job performance and for interactional justice perception as a contextual contingency of this relationship.

\section{Theoretical Background and Hypothesis Development}

\subsection{Perfectionism and Job Performance}

Job performance usually consists of two main components, such as task performance and OCB $[15,16]$. While task performance as an in-role behavior is defined as fulfilling the requirements of a job description, $\mathrm{OCB}$ as an extra-role behavior refers to individuals' discretionary behaviors without expecting formal rewards and contributing to the effectiveness of the organization [17]. Understanding the significance of job performance as a key predictor of organizational effectiveness, organizations have searched for factors that enhance job performance at work [18]. Prior research has examined various antecedents, such as individual, social and job factors, that affect job performance [15]. Among various factors, an abundant amount of research has been conducted to investigate specific, individual characteristics as a critical determinant of individual job performance [18,19]. 
For instance, scholars have identified the Big Five personality traits and self-efficacy as antecedents of job performance [19].

Following this line of research, this study aims to enhance our understanding of job performance, including task performance and $\mathrm{OCB}$, by examining an employee's perfectionism as a potential predictor, focusing on SOP. SOP is considered a strong motivational component for employees in completing their assigned tasks at work $[3,20]$. According to Ocampo et al. [2], SOP can be characterized as perfectionistic strivings, which have been known to improve positive performance consequences [21,22]. Previous studies also showed that SOP is positively related to adaptive work habits, constructive striving, higher levels of task orientation and high achievement [23,24].

Similarly, scholars have shown that SOP has positive relationships with personal characteristics, such as conscientiousness and persistence, which have been found to be significant determinants of employees' job performance [20,25]. Achievement striving and dutifulness, which are the main components of conscientiousness, are significantly associated with various indicators of task performance [19]. In addition, persistence has been known to have positive relationships with different performance indicators [26]. Taken together, we expect that employees with high levels of SOP are more likely to set high standards and invest more effort to meet those standards, thereby exhibiting higher task performance.

Hypothesis 1 (H1). Employee's self-oriented perfectionism (SOP) is positively related to task performance.

According to Podsakoff et al. [27], individual difference is one of the major antecedents of OCB and deserves to get attention from organizations. Since perfectionists want to be perfect in every aspect, employees with a high level of SOP may focus not only on their in-role performance (e.g., task performance) but also on their extra-role performance (e.g., OCB) [28]. Specifically, employees with high levels of SOP are expected to perceive OCB as a part of their job role, hold broad role definitions and display a wider set of work behaviors [29]. Previous research has noted that role definition is a significant factor in predicting OCB [30]. Furthermore, SOP has positive relationships with personal characteristics, such as conscientiousness, positive affectivity, self-efficacy and a proactive personality, which are important personality traits to positively affect OCB [31,32]. Therefore, we expect that employees with high SOP tend to perform OCB because they have broader role definitions and are more likely to embrace extra-role behaviors as part of their job than those with low SOP.

Hypothesis 2 (H2). Employee's self-oriented perfectionism (SOP) is positively related to organizational citizenship behavior $(O C B)$.

\subsection{Perfectionism, Interactional Justice and Job Performance}

Interactional justice is defined as the interpersonal treatment employees receive from their managers [33]. Since a supervisor plays a critical role and exerts significant influence on their individual followers' attitudes and behaviors in the workplace, it is expected that interactional justice is an important, situational factor that influences employees' job performance $[34,35]$. Prior studies found that interactional justice is a significant contextual factor that affects a broad range of outcomes, including job attitudes, behaviors and job performance [36-38]. For example, Van Dijke et al. [35] argued that low interactional justice can be a threat to employees that may undermine their intrinsic motivation and, in turn, in-role performance and OCB. Given the key role of supervisors in administering just treatment that can occur in the entire social interactions with their employees on a daily basis [39], along with the prevalence of low interactional justice in work settings [40], interactional justice seems to be the most relevant, situational cue that might relate to the activation of the motivational aspect of perfectionism when it comes to understanding the 
positive implication of perfectionism in individuals' functioning at work. Thus, this study explores the critical role of interactional justice that activates or negates the effects of SOP on job performance based on trait activation theory.

According to trait activation theory $[11,41]$, the extent to which individual characteristics are activated can be affected by trait-relevant, situational factors. This study investigates interactional justice as a potential situational cue that influences the relationship between SOP and job performance. Social exchange theory suggests that individuals who receive benefits from others feel a sense of obligation to reciprocate in some way to maintain their social exchange relationship [42]. Interactional justice can influence employees' sense of obligation toward their organization or coworkers, which may encourage them to make contributions to organizational effectiveness [30]. On the basis of this norm of reciprocity [43], employees who have received fair treatment from their supervisor tend to exhibit positive attitudes and behaviors. Since task performance and OCB are highly valued by organizations, employees may decide to put more effort into engaging in job performance as a return for high interactional justice. Favorable treatment and support from a supervisor can be powerful rewards for employees, driving them to achieve high level of job performance, regardless of traits such as SOP. Hence, a high level of interactional justice is likely to negate the effects of SOP on job performance.

On the contrary, low interactional justice contexts can serve as a trait-relevant, situational cue that activates SOP's effect on job performance. When employees recognize a lack of fair treatment from their supervisor, they may decide to reduce their effort on achieving high job performance because they feel less obligation to perform such beneficial behaviors in accordance with social exchange theory. However, the level of job performance could be altered depending on employees' traits, such as SOP, in such unfair situations. Since highly self-oriented perfectionists tend to strive for high achievement and are internally motivated to be perfect in every aspect [2], they are more likely to demonstrate a high level of task performance and OCB even when they perceive an unfavorable context, such as a low level of interactional justice. Similarly, scholars have shown how political skill can be activated to enhance task performance when organizational justice is low [44]. In contrast, employees with low SOP who do not have a tendency to strive for perfection are less likely to show a high level of job performance when interactional justice is low. Thus, we propose that SOP has stronger positive effects on job performance when interactional justice is low as compared to when it is high.

Hypothesis 3 (H3). Interactional justice moderates the relationship between self-oriented perfectionism (SOP) and task performance such that the positive relationship is stronger when interactional justice is low than when interactional justice is high.

Hypothesis 4 (H4). Interactional justice moderates the relationship between self-oriented perfectionism (SOP) and organizational citizenship behavior $(O C B)$ such that the positive relationship is stronger when interactional justice is low than when interactional justice is high.

\section{Method}

\subsection{Participants and Procedures}

We collected data from six manufacturing firms and three customer service firms located in Seoul, Korea, by distributing separate surveys for subordinates and their immediate supervisors in their subordinate-supervisor dyads. The survey packet, which included both subordinate and supervisor surveys, along with a reply envelope, was delivered directly to the researchers after completing the questionnaires. In order to match the dyads afterwards, we assigned the same code number to each survey. One supervisor filled out a questionnaire for only one subordinate. We assured all participants that their responses would remain confidential. To minimize common method variance, we collected data from different sources, such as supervisors and subordinates. For example, subordinates rated their age, gender, conscientiousness, three perfectionism dimensions (self-oriented 
perfectionism, other-oriented perfectionism and socially prescribed perfectionism) and interactional justice. Supervisors rated their subordinates' task performance and OCB.

The survey was administered to 150 supervisor-subordinate dyads, and a total of 121 dyads were finally used in our analysis. From each company, different numbers of dyads were included in our sample, ranging from 1 dyad to 38 dyads. Out of the subordinates, $58.7 \%$ were male, and the subordinates had an average age of 30.64 years $(S D=4.78)$. Out of the 121 supervisors, $70.2 \%$ were male, and the average age was 38.4 years $(S D=5.93)$. The most frequent education level was the four-year college: $59.5 \%$ for subordinates and $61.2 \%$ for supervisors. The industry sectors included in our sample were manufacturing $(66.7 \%)$ and service $(33.3 \%)$.

\subsection{Measures}

We performed hierarchical regression analyses to test the hypotheses for each outcome variable, i.e., task performance and OCB. To do so, we collected data by using the measures below. Using the back-translation procedure [45], the measures initially developed in English were translated to Korean. We applied a seven-point Likert response scale ranging from 1 (strongly disagree) to 7 (strongly agree).

Self-Oriented Perfectionism (SOP). We assessed SOP using fifteen items from the Multidimensional Perfectionism Scale developed by Hewitt and Flett [3]. Sample items included "When I am working on something, I cannot relax until it is perfect." and "One of my goals is to be perfect in everything I do." $(\alpha=93)$.

Job Performance. Supervisors evaluated their subordinates' job performance, including task performance (7 items), and OCB (14 items) developed by Williams and Anderson [46]. An example item of task performance is "This employee fulfills all responsibilities required by his/her job." $(\alpha=92)$. A sample item of OCB is "This employee helps others who have heavy workloads." $(\alpha=90)$.

Interactional Justice. Interactional justice was measured with 8 items developed by Colquitt [47]. Sample items are "Has (he/she) treated you in a polite manner?" and "Has (he/she) been candid in (his/her) communications with you?" ( $\alpha=94)$.

Control Variables. Based on a review of previous literature, we controlled several variables, including age, gender, conscientiousness and two other perfectionism dimensions (i.e., other-oriented perfectionism and socially prescribed perfectionism). Existing studies have shown that conscientiousness and two other perfectionism dimensions could be potential confounding variables that may influence the relationships between SOP and outcomes [25]. Conscientiousness was measured with 10 items from Goldberg [48], and sample items included "I like order." and "I am exacting in my work." $(\alpha=84)$. The Multidimensional Perfectionism Scale developed by Hewitt and Flett [3] was used to assess other-oriented perfectionism ( $\alpha=84$; “If I ask someone to do something, I expect it to be done flawlessly") and socially prescribed perfectionism $(\alpha=82$; "People expect nothing less than perfection from $\mathrm{me}^{\prime \prime}$ ).

\section{Results}

The means, standard deviations and intercorrelations of major variables are shown in Table 1. Hypothesis 1 predicted that an employee's SOP is positively related to task performance. As indicated in Table 2, the results of the hierarchical regression analysis showed that $\mathrm{SOP}$ was significantly and positively related to an employee's task performance $(\beta=0.24, p<0.05)$. Thus, Hypothesis 1 was supported. Hypothesis 2 proposed that an employee's SOP would have a positive relationship with OCB. The results in Table 3 indicated that SOP was marginally and positively related to OCB $(\beta=0.22, p<0.10)$. 
Table 1. Means, standard deviations and correlations among study variables.

\begin{tabular}{|c|c|c|c|c|c|c|c|c|c|c|c|}
\hline & Mean & S. D. & 1 & 2 & 3 & 4 & 5 & 6 & 7 & 8 & 9 \\
\hline 1. Age $^{a}$ & 30.64 & 4.78 & & & & & & & & & \\
\hline 2. Gender ${ }^{a}$ & 1.41 & 0.49 & $-0.39 * * *$ & & & & & & & & \\
\hline 3. Conscientiousness ${ }^{a}$ & 4.77 & 0.81 & 0.13 & $-0.25 * *$ & $(0.84)$ & & & & & & \\
\hline 4. Other-oriented perfectionism ${ }^{a}$ & 4.32 & 0.67 & 0.12 & -0.10 & $0.21 *$ & $(0.84)$ & & & & & \\
\hline 5. Socially prescribed perfectionism ${ }^{a}$ & 4.08 & 0.67 & 0.06 & -0.02 & 0.12 & $0.53^{* * *}$ & $(0.82)$ & & & & \\
\hline 6. Self-oriented perfectionism (SOP) ${ }^{a}$ & 5.18 & 0.84 & -0.03 & -0.01 & $0.44^{* * *}$ & $0.53^{* * *}$ & $0.44^{* * *}$ & $(0.93)$ & & & \\
\hline 7. Interactional justice ${ }^{a}$ & 5.38 & 1.08 & -0.07 & 0.10 & 0.15 & -0.03 & -0.09 & 0.18 & $(0.94)$ & & \\
\hline 8. Task performance ${ }^{\mathrm{b}}$ & 5.84 & 0.81 & 0.06 & 0.03 & 0.16 & 0.15 & 0.03 & 0.25 & $0.38^{* * *}$ & $(0.92)$ & \\
\hline 9. $\mathrm{OCB}^{\mathrm{b}}$ & 5.62 & 0.75 & 0.09 & 0.16 & 0.05 & 0.04 & 0.03 & 0.17 & $0.33^{* * *}$ & $0.78^{* * *}$ & $(0.90)$ \\
\hline
\end{tabular}

Note. $\mathrm{N}=121$. Reliabilities are on the diagonal in parentheses. ${ }^{\mathrm{a}}$ Focal employees' rating. ${ }^{\mathrm{b}}$ Managerial rating. ${ }^{*} p<0.05 ;{ }^{* *} p<0.01 ;{ }^{* * *} p<0.001$ (two-tailed).

Table 2. Hierarchical regression analysis results for task performance ${ }^{\mathrm{a}}$.

\begin{tabular}{|c|c|c|c|c|}
\hline Variables & Model 1 & Model 2 & Model 3 & Model 4 \\
\hline \multicolumn{5}{|l|}{ Step 1: Control variables $\mathrm{b}$} \\
\hline Age & 0.07 & 0.10 & 0.10 & 0.11 \\
\hline Gender & 0.12 & 0.10 & 0.06 & 0.06 \\
\hline Conscientiousness & 0.16 & 0.07 & 0.03 & 0.03 \\
\hline Other-oriented perfectionism & 0.16 & 0.07 & 0.10 & 0.12 \\
\hline \multicolumn{2}{|l|}{ Step 2: Main effect } & -0.13 & -0.07 & -0.05 \\
\hline Self-oriented perfectionism (SOP) & & 0.24 * & 0.16 & 0.11 \\
\hline \multicolumn{5}{|l|}{ Step 3: Main effect } \\
\hline Interactional justice & & & $0.35^{* * *}$ & $0.36^{* * *}$ \\
\hline \multicolumn{5}{|l|}{ Step 4: Moderating effect } \\
\hline $\mathrm{SOP} \times$ Interactional justice & & & & $-0.16^{\dagger}$ \\
\hline Overall F & 1.36 & $1.84^{\dagger}$ & $4.04^{* *}$ & $4.06^{* * *}$ \\
\hline $\mathrm{R}^{2}$ & 0.01 & 0.04 & 0.15 & 0.17 \\
\hline F change & & $4.06^{*}$ & $15.82^{* * *}$ & $3.55^{\dagger}$ \\
\hline $\mathrm{R}^{2}$ change & & 0.03 & 0.11 & 0.02 \\
\hline
\end{tabular}

Note. $\mathrm{N}=121 .{ }^{\mathrm{a}}$ Entries are standardized regression coefficients. ${ }^{\mathrm{b}}$ These are standardized variables. ${ }^{\dagger} p<0.10$ ${ }^{*} p<0.05 ;{ }^{* *} p<0.01 ;{ }^{* * *} p<0.001$ (two-tailed).

In order to test the moderating effects, we performed two sets of hierarchical regression analyses. In the first step, control variables were included. SOP was entered in Step 2, followed by interactional justice. Finally, the interaction term of SOP and interactional justice was entered in Step 3. Hypothesis 3 suggested that the relationship between SOP and task performance is moderated by interactional justice such that it would be stronger when interactional justice is low. As shown in Table 2, the interaction term of SOP and interactional justice on task performance was marginally significant $(\beta=-0.16$, $p<0.10)$. Hypothesis 4 proposed that the relationship between SOP and OCB is moderated by interactional justice such that it would be stronger when interactional justice is low. From Table 3, the interaction term of SOP and interactional justice on OCB was significant $(\beta=-0.18, p<0.05)$. 
Table 3. Hierarchical regression analysis results for OCB ${ }^{a}$.

\begin{tabular}{|c|c|c|c|c|}
\hline Variables & Model 1 & Model 2 & Model 3 & Model 4 \\
\hline \multicolumn{5}{|l|}{ Step 1: Control variables ${ }^{b}$} \\
\hline Age & $0.17^{\dagger}$ & $0.19^{\dagger}$ & 0.20 * & $0.21 *$ \\
\hline Gender & $0.25 *$ & 0.23 * & $0.20 *$ & $0.20 *$ \\
\hline Conscientiousness & 0.09 & 0.00 & 0.03 & -0.03 \\
\hline Other-oriented perfectionism & 0.03 & -0.06 & -0.03 & -0.01 \\
\hline Socially prescribed perfectionism & 0.00 & -0.04 & 0.01 & 0.04 \\
\hline \multicolumn{5}{|l|}{ Step 2: Main effect } \\
\hline Self-oriented perfectionism (SOP) & & $0.22^{\dagger}$ & 0.15 & 0.10 \\
\hline \multicolumn{5}{|l|}{ Step 3: Main effect } \\
\hline Interactional justice & & & $0.31^{* *}$ & $0.31 * *$ \\
\hline \multicolumn{5}{|l|}{ Step 4: Moderating effect } \\
\hline $\mathrm{SOP} \times$ Interactional justice & & & & $-0.18 *$ \\
\hline Overall F & 1.49 & $1.84^{\dagger}$ & $3.38^{* *}$ & $3.60 * *$ \\
\hline $\mathrm{R}^{2}$ & 0.02 & 0.04 & 0.12 & 0.15 \\
\hline F change & & $3.43^{\dagger}$ & $11.59 * *$ & $4.42 *$ \\
\hline $\mathrm{R}^{2}$ change & & 0.03 & 0.08 & 0.03 \\
\hline
\end{tabular}

Note. $\mathrm{N}=121 .{ }^{\mathrm{a}}$ Entries are standardized regression coefficients. ${ }^{\mathrm{b}}$ These are standardized variables. ${ }^{\dagger} p<0.10$ ${ }^{*} p<0.05 ; * *<0.01$ (two-tailed).

As shown in Figures 1 and 2, we plotted the significant interaction effects using Aiken and West's [49] procedure of $\pm 1 \mathrm{SD}$. The simple slope tests showed that the relationship between self-oriented perfectionism and task performance is significant only when interactional justice is low $(b=0.27, t=2.10, p<0.05)$, but not significant when interactional justice is high ( $b=-0.04, t=-0.26, \mathrm{n}$. s.). Thus, Hypothesis 3 was supported (see Figure 1 ). With the plot of interaction shown in Figure 2, the finding provided support for Hypothesis 4 that the relationship between SOP and OCB was stronger when interactional justice was low $(b=0.28, t=2.11, p<0.05)$ but not significant when interactional justice is high $(b=-0.08, t=-0.48$, n. s. $)$.

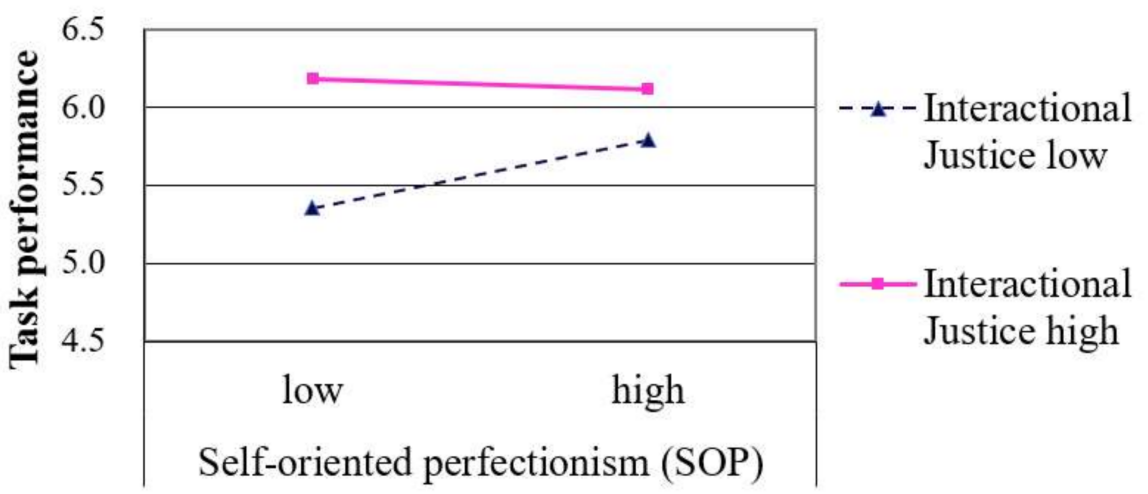

Figure 1. Moderated effect of interactional justice on the relationship between SOP and task performance. 


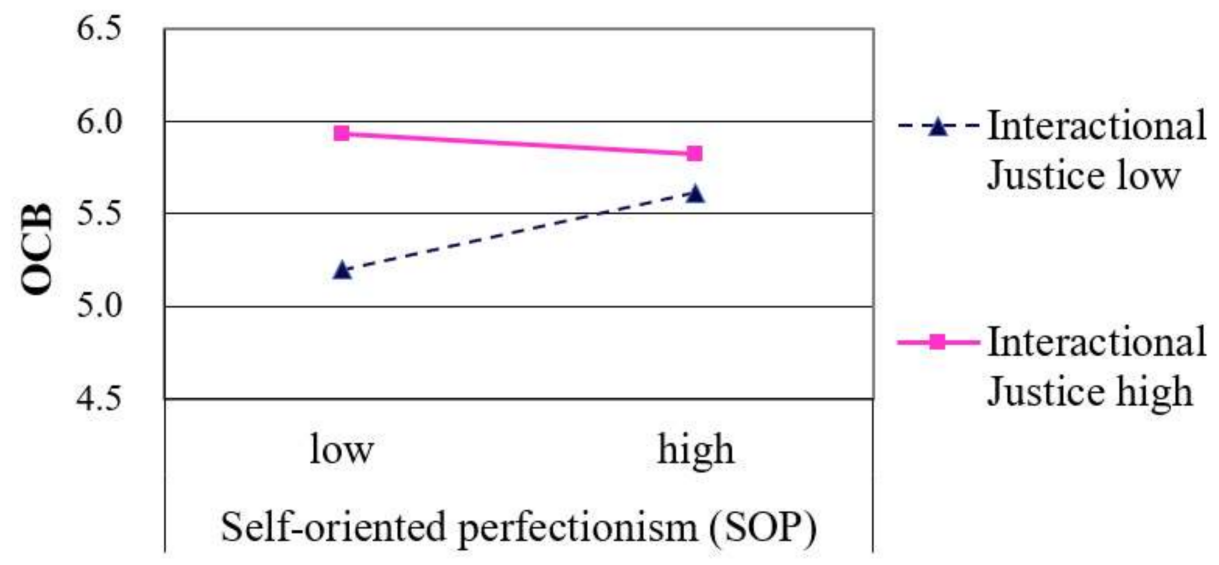

Figure 2. Moderated effect of interactional justice on the relationship between SOP and OCB.

\section{Discussion}

\subsection{Overall Findings}

Although perfectionism is often found and appreciated in the workplace, there is a paucity of research examining the role of perfectionism in organizational contexts [9]. The current study explored an important and interesting research question regarding the positive effects of employee perfectionism in organizations. As we hypothesized, our results revealed the positive impact of SOP on job performance. Moreover, our research proposed the moderating role of interactional justice in the relationship between SOP and job performance. Applying trait activation theory, our findings exhibited that the SOP trait's effect on job performance was activated when interactional justice was low rather than when it was high. These findings seem to be consistent with prior research indicating the positive effects of perfectionism, particularly perfectionistic strivings, on various performance consequences [2]. Additionally, from the trait-activation perspective, we demonstrated the role of interactional justice as a trait-relevant situational cue to the manifestation of perfectionism at work.

Previous research has shown somewhat mixed findings and inconsistent conclusions regarding the influence of employee perfectionism at work. Harari et al.'s [23] metaanalysis concluded that perfectionism was a destructive phenomenon in the workplace, while Ocampo et al.'s [2] review paper reached a different conclusion which argues both positive and negative implications of perfectionism in terms of individuals' functioning at work. We believe that our results can contribute to addressing such disagreement that exists in previous literature and develop a fuller understanding of perfectionism in organizations by exploring the possibility that perfectionism does not result in detrimental outcomes under certain conditions.

\subsection{Theoretical and Practical Implications}

This study offers several theoretical implications. First, we proposed and empirically demonstrated the positive effects of perfectionism in the workplace. Prior research has focused on the detrimental effects of perfectionism on outcomes such as stress, anxiety and depression [23]. In this research, however, we highlighted the positive aspect of perfectionism by demonstrating that perfectionism can be a meaningful predictor of employees' job performance beyond the effects of the other two dimensions of perfectionism (i.e., other-oriented perfectionism and socially prescribed perfectionism) and conscientiousness. Specifically, our findings exhibited that SOP is positively and significantly related to task performance, whereas SOP is marginally and positively related to OCB. Although OCB is an important type of job performance, self-oriented perfectionists may hesitate to put much effort into performing OCB to their level of perfection, given their limited resources, because it is an extra-role behavior (e.g., conservation of resources theory) [2]. In further re- 
search, it would be beneficial to examine the main effects of SOP on various work behaviors. For example, although we did not include CWB in our study as an outcome variable along with task performance and $\mathrm{OCB}, \mathrm{CWB}$ should be considered in future research to better understand the comprehensive influence of perfectionism on employees' job performance, considering its established importance as a distinct dimension of job performance [50].

Moreover, our research applied trait activation theory and exhibited the interaction effect of SOP and interactional justice on job performance. A recent review of perfectionism suggested the importance of examining the moderators of the relationships between perfectionism and outcomes [2]. To fill in the gap, our research explored interactional justice as a situational cue that triggers the trait of SOP to activate and engage in job performance. When there is a low level of interactional justice, employees do not perceive fair treatment or support from their supervisors. In such unfair situations, the trait of SOP tends to be activated to promote job performance. From the trait activation perspective, future researchers should consider other situational cues that may interact with perfectionism on various work outcomes, such as coworker influence, job characteristics and organizational culture.

Second, our study gives insights to the justice literature by investigating the moderating role of interactional justice in the relationship between SOP and job performance. Prior research has mostly focused on the main effect of interactional justice on work attitudes and behaviors [34]. Our research has shown how interactional justice may serve as a contextual cue that influences the perfectionism-job performance relationship. Specifically, our results showed that the interaction of SOP and interactional justice was significant on OCB but only marginally significant on task performance. The strong, main effect of SOP may result in a marginally significant interaction effect of SOP and interactional justice on task performance. Future research should continue to explore other dimensions of justice, as well as interactional justice, as important situational cues and examine their moderating roles in trait-outcome relationships.

Lastly, this study provides empirical support for job performance by exploring SOP as a common predictor of task performance and OCB. Although it is common to find employees with high perfectionistic tendencies in organizations, little attention has been given to investigating the effects of perfectionism [23]. As our findings exhibited, perfectionism, especially SOP, can be a potential predictor that can enhance job performance in the workplace. Moreover, although it was not hypothesized, our results show the main effects of interactional justice on job performance as well. In future research, it would be beneficial to search for factors that facilitate both task performance and OCB.

In addition, this study offers practical implications. First of all, managers or supervisors need to recognize the positive potentials of employees' perfectionistic tendencies, particularly self-oriented perfectionism, which can affect subordinates' job performances that are highly valued in organizations. In this context, it is necessary for organizations to consider perfectionism in selection procedures or training programs [51]. Second, the importance of interactional justice should be recognized by supervisors to improve employees' in-role, as well as extra-role, activities. Thus, managers should find a way to build a high level of interactional justice by offering fair treatment and frequent communication with respect and dignity to their employees, which will help them to achieve a high level of job performance, regardless of their perfectionistic tendency.

\subsection{Limitations and Future Research}

This research is not without limitations. First, the causal relationships may not be clearly interpreted because this study employed a cross-sectional design and collected data at a single time point. Therefore, the direction of the relationship between SOP and job performance should be investigated using the longitudinal study design. Second, this study focused only on a limited number of variables. Future research needs to include more variables, such as mediators and other moderators, to deepen our understanding of how and when employee perfectionism shapes their attitudes and work behaviors. For example, examining the moderating effects of other various contextual factors (e.g., task 
characteristics) on SOP-job performance linkages could be meaningful in further research. Third, as this study only used samples from manufacturing and service industries, it would be beneficial for scholars to collect data from various types of industry sector to increase the generalizability of our findings in their future research. Last, future research may need to adopt a multilevel approach to fully understand the intrapersonal and interpersonal effects of employee SOP in the workplace.

\section{Conclusions}

Recent research on perfectionism has shown the growing number of perfectionists over the past three decades [1]. Moreover, employees in today's workplaces are even encouraged to strive for perfection in doing their work [52]. Recognizing the increasing importance of perfectionism in the work context, our results demonstrated the unique and incremental predictive power of SOP on job performance, especially task performance. More importantly, this research applied trait activation theory and highlighted the critical role of interactional justice as a boundary condition altering the relationship between SOP and OCB. With these findings, this study could shed light on the positive implication of employee SOP in predicting their job performance under certain conditions in organizations. We hope this research helps organizational scholars have a better understanding of perfectionism in the workplace.

Author Contributions: Conceptualization, M.K. and S.Y.; methodology, S.Y.S.; validation, M.K. and S.L.K.; formal analysis, S.L.K.; supervision, S.Y.; data curation, S.Y.S.; writing-original draft preparation, M.K.; writing - review and editing, S.L.K.; project administration, S.Y.; funding acquisition, S.L.K. All authors have read and agreed to the published version of the manuscript.

Funding: This work was supported by Incheon National University (International Cooperative) Research Grant in 2021.

Institutional Review Board Statement: Ethics approval was not required since the questionnaire survey for the article did not identify specific individuals from the collected information and the participation was entirely voluntary.

Informed Consent Statement: Informed consent was obtained from all subjects involved in the study.

Data Availability Statement: Dataset is available from the corresponding author on reasonable request.

Conflicts of Interest: The authors declare no conflict of interest.

\section{References}

1. Curran, T.; Hill, A.P. Perfectionism is increasing over time: A meta-analysis of birth cohort differences from 1989 to 2016. Psychol. Bull. 2019, 145, 410-429. [CrossRef] [PubMed]

2. Ocampo, A.C.G.; Wang, L.; Kiazad, K.; Restubog, S.L.D.; Ashkanasy, N.M. The relentless pursuit of perfectionism: A review of perfectionism in the workplace and an agenda for future research. J. Organ. Behav. 2020, 41, 144-168. [CrossRef]

3. Hewitt, P.L.; Flett, G.L. Perfectionism in the self and social contexts: Conceptualization, assessment, and association with psychopathology. J. Personal. Soc. Psychol. 1991, 60, 456-470. [CrossRef]

4. Stoeber, J.; Lalova, A.V.; Lumley, E.J. Perfectionism,(self-) compassion, and subjective well-being: A mediation model. Pers. Indiv. Differ. 2020, 154, 109708. [CrossRef]

5. Hamachek, D.E. Psychodynamics of normal and neurotic perfectionism. Psychol. A J. Hum. Behav. 1978, 15, 27-33.

6. Stoeber, J. How other-oriented perfectionism differs from self-oriented and socially prescribed perfectionism: Further findings. J. Psychopathol. Behav. 2015, 37, 611-623. [CrossRef]

7. Frost, R.O.; Marten, P.; Lahart, C.; Rosenblate, R. The dimensions of perfectionism. Cognitive Ther. Res. 1990, 14, 449-468. [CrossRef]

8. Kim, S.L.; Kim, M.; Yun, S. What do we need for creativity? The interaction of perfectionism and overall justice on creativity. Pers. Rev. 2017, 46, 154-167. [CrossRef]

9. Ozbilir, T.; Day, A.; Catano, V.M. Perfectionism at work: An investigation of adaptive and maladaptive perfectionism in the workplace among Canadian and Turkish employees. Appl. Psychol.-Int. Rev. 2015, 64, 252-280. [CrossRef]

10. Hochwarter, W.A.; Witt, L.A.; Treadway, D.C.; Ferris, G.R. The interaction of social skill and organizational support on job performance. J. Appl. Psychol. 2006, 91, 482-489. [CrossRef] [PubMed]

11. Tett, R.; Burnett, D. A personality trait-based interactionist model of job performance. J. Appl. Psychol. 2003, 88, 500-517. [CrossRef] [PubMed] 
12. Mischel, W. Toward a cognitive social learning reconceptualization of personality. Psychol. Rev. 1973, 80, 252-283. [CrossRef]

13. Lind, E.A. Fairness heuristic theory: Justice judgements as pivotal cognitions in organizational relations. In Advances in Organizational Justice; Greenberg, J., Cropanzano, R., Eds.; Stanford University Press: Stanford, CA, USA, 2001 ; pp. 56-88.

14. Van den Bos, K.; Lind, E.A.; Wilke, H.A.M. The psychology of proceduraland distributive justice viewed from the perspective of fairness heuristic theory. In Justice in the Workplace: Vol. 2. From Theory to Practice; Cropanzano, R., Ed.; Erlbaum: Mahwah, NJ, USA, 2001; pp. 49-66.

15. Rich, B.L.; Lepine, J.A.; Crawford, E.R. Job engagement: Antecedents and effects on job performance. Acad. Manag. J. 2010, 53, 617-635. [CrossRef]

16. Yun, S.; Takeuchi, R.; Liu, W. Employee self-enhancement motives and job performance behaviors: Investigating the moderating effects of employee role ambiguity and managerial perceptions of employee commitment. J. Appl. Psychol. 2007, 92, 745-756. [CrossRef]

17. Organ, D.W. Organizational Citizenship Behavior: The Good Soldier Syndrome; Lexington Books, DC Heath and Com: Lexington, MA, USA, 1988.

18. Le, H.; Oh, I.S.; Robbins, S.B.; Ilies, R.; Holland, E.; Westrick, P. Too much of a good thing: Curvilinear relationships between personality traits and job performance. J. Appl. Psychol. 2011, 96, 113-133. [CrossRef]

19. Barrick, M.R.; Mount, M.K. The big five personality dimensions and job performance: A meta-analysis. Pers. Psychol. 1991, 44, 1-26. [CrossRef]

20. Kobori, O.; Yamagata, S.; Kijima, N. The relationship of temperament to multidimensional perfectionism trait. Pers. Indiv. Differ. 2005, 38, 203-211. [CrossRef]

21. Sherry, S.B.; Hewitt, P.L.; Sherry, D.L.; Flett, G.L.; Graham, A.R. Perfectionism dimensions and research productivity in psychology professors: Implications for understanding the (mal) adaptiveness of perfectionism. Can. J. Beh. Sci. 2010, 42, 273-283. [CrossRef]

22. Stoeber, J.; Rambow, A. Perfectionism in adolescent school students: Relations with motivation, achievement, and well-being. Pers. Indiv. Differ. 2007, 42, 1379-1389. [CrossRef]

23. Harari, D.; Swider, B.W.; Steed, L.B.; Breidenthal, A.P. Is perfect good? A meta-analysis of perfectionism in the workplace. J. Appl. Psychol. 2018, 103, 1121-1144. [CrossRef] [PubMed]

24. Mills, J.S.; Blankstein, K.R. Perfectionism, intrinsic vs extrinsic motivation, and motivated strategies for learning: A multidimensional analysis of university students. Pers. Indiv. Differ. 2000, 29, 1191-1204. [CrossRef]

25. Stoeber, J.; Otto, K.; Dalbert, C. Perfectionism and the Big Five: Conscientiousness predicts longitudinal increases in self-oriented perfectionism. Pers. Indiv. Differ. 2009, 47, 363-368. [CrossRef]

26. Robbins, S.B.; Lauver, K.; Le, H.; Davis, D.; Langley, R.; Carlstrom, A. Do psychosocial and study skill factors predict college outcomes? A meta-analysis. Psychol. Bull. 2004, 130, 261-288. [CrossRef]

27. Podsakoff, P.M.; MacKenzie, S.B.; Paine, J.B.; Bachrach, D.G. Organizational citizenship behaviors: A critical review of the theoretical and empirical literature and suggestions for future research. J. Manag. 2000, 26, 513-563. [CrossRef]

28. Periasamy, S.; Ashby, J.S. Multidimensional Perfectionism and Locus of Control: Adaptive vs. Maladaptive Perfectionism. J. Coll. Stud. Psychother. 2002, 17, 75-86. [CrossRef]

29. Beauregard, A.T. Perfectionism, self-efficacy and OCB: The moderating role of gender. Pers. Rev. 2012, 41, 590-608. [CrossRef]

30. Kamdar, D.; McAllister, D.J.; Turban, D.B. "All in a Day's Work": How follower individual differences and justice perceptions predict OCB role definitions and behaviors. J. Appl. Psychol. 2006, 4, 841-855. [CrossRef]

31. Lapierre, L.M.; Hackett, R.D. Trait conscientiousness, leader-member exchange, job satisfaction and organizational citizenship behaviour: A test of an integrative model. J. Occup. Organ. Psych. 2007, 80, 539-554. [CrossRef]

32. Michel, J.W. Antecedents of organizational citizenship behaviors: Examining the incremental validity of self-interest and prosocial motives. J. Leadership Org. Stud. 2017, 24, 385-400. [CrossRef]

33. Bies, R.J.; Moag, J.F. Interactional justice: Communication criteria of fairness. In Research on Negotiations in Organizations; Lewicki, R.J., Sheppard, B.H., Bazerman, M.H., Eds.; JAI Press: Greenwich, CT, USA, 1986; Volume 1, pp. 43-55.

34. Ambrose, M.L.; Schminke, M.; Mayer, D.M. Trickle-down effects of supervisor perceptions of interactional justice: A moderated mediation approach. J. Appl. Psychol. 2013, 98, 678-689. [CrossRef] [PubMed]

35. Van Dijke, M.; Leunissen, J.M.; Wildschut, T.; Sedikides, C. Nostalgia promotes intrinsic motivation and effort in the presence of low interactional justice. Organ. Behav. Hum. Dec. 2019, 150, 46-61. [CrossRef]

36. Cohen-Charash, Y.; Spector, P.E. The role of justice in organizations: A meta-analysis. Organ. Behav. Hum. Dec. 2001, 86, 278-321. [CrossRef]

37. Colquitt, J.A.; Conlon, D.E.; Wesson, M.J.; Porter, C.O.; Ng, K.Y. Justice at the millennium: A meta-analytic review of 25 years of organizational justice research. J. Appl. Psychol. 2001, 86, 425-445. [CrossRef]

38. Zapata-Phelan, C.P.; Colquitt, J.A.; Scott, B.A.; Livingston, B. Procedural justice, interactional justice, and task performance: The mediating role of intrinsic motivation. Organ. Behav. Hum. Dec. 2009, 108, 93-105. [CrossRef]

39. He, W.; Fehr, R.; Yam, K.C.; Long, L.R.; Hao, P. Interactional justice, leader-member exchange, and employee performance: Examining the moderating role of justice differentiation. J. Organ. Behav. 2017, 38, 537-557. [CrossRef]

40. Scott, B.A.; Garza, A.S.; Conlon, D.E.; Kim, Y.J. Why do managers act fairly in the first place? A daily investigation of "hot" and "cold" motives and discretion. Acad. Manag. J. 2014, 57, 1571-1591. [CrossRef] 
41. Haaland, S.; Christiansen, N. Implications of trait-activation theory for evaluating the construct validity of assessment center ratings. Pers. Psychol. 2002, 55, 137-165. [CrossRef]

42. Blau, P.M. Exchange and Power in Social Life; John Wiley: New York, NY, USA, 1964.

43. Gouldner, A.W. The norm of reciprocity: A preliminary statement. Am. Sociol. Rev. 1960, 25, 161-177. [CrossRef]

44. Andrews, M.C.; Kacmar, K.M.; Harris, K.J. Got political skill? The impact of justice on the importance of political skill for job performance. J. Appl. Psychol. 2009, 94, 1427-1437. [CrossRef] [PubMed]

45. Brislin, R. Applied Cross Cultural Psychology; Sage: Newbury Park, CA, USA, 1990.

46. Williams, L.J.; Anderson, S.E. Job satisfaction and organizational commitment as predictors of organizational citizenship and in-role behaviors. J. Manag. 1991, 17, 601-617. [CrossRef]

47. Colquitt, J.A. On the dimensionality of organizational justice: A construct validation of a measure. J. Appl. Psychol. 2001, 86, 386-400. [CrossRef] [PubMed]

48. Goldberg, L.R. International Personality Item Pool. 1999. Available online: http:/ /ipip.ori.org (accessed on 17 January 2022).

49. Aiken, L.S.; West, S.G. Multiple Regression: Testing and Interpreting Interactions; Sage: Newbury Park, CA, USA, 1991.

50. Rotundo, M.; Sackett, P.R. The relative importance of task, citizenship, and counterproductive performance to global ratings of job performance: A policy-capturing approach. J. Appl. Psychol. 2002, 87, 66-80. [CrossRef] [PubMed]

51. Tan, H.H.; Tan, M.L. Organizational citizenship behavior and social loafing: The role of personality, motives, and contextual factor. J. Psychol. 2008, 142, 89-108. [CrossRef] [PubMed]

52. Guo, L.; Chiang, J.T.J.; Mao, J.Y.; Chien, C.J. Abuse as a reaction of perfectionistic leaders: A moderated mediation model of leader perfectionism, perceived control, and subordinate feedback seeking on abusive supervision. J. Occup. Organ. Psych. 2020, 93, 790-810. [CrossRef] 